\title{
Limit Analysis Assessment of Experimental Behavior of Arches Reinforced with GFRP Materials
}

\author{
Ismael Basilio $^{\mathrm{a}}$, Roberto Fedele ${ }^{\mathrm{b}}$, Paulo B. Lourenço ${ }^{\mathrm{c}}$ and Gabriele Milani ${ }^{\mathrm{d}^{*}}$ \\ ${ }^{a}$ Formerly, Department of Construction and Health, Danish Building Research Institute (SBi) Aalborg University - \\ CPH A.C. Meyers Voenge 15, 2450 Copenhagen SV - Denmark \\ ${ }^{b}$ Department of Civil and Environmental Engineering (DICA), Politecnico di Milano, PiazzaLeonardo da Vinci 32, \\ 20133 Milan, Italy \\ ${ }^{c}$ Department of Civil Engineering, University of Minho, Campus de Azurem, Guimaraes, Portugal \\ ${ }^{d}$ Department of Architecture, Built Environment and Construction Engineering (ABC), Politecnico diMilano, Piazza \\ Leonardo da Vinci 32, 20133 Milan, Italy
}

\begin{abstract}
In this paper, a comparison between results furnished by a 3D FE upper bound limit analysis and experimental results for some reinforced masonry arches tested at the University of Minho (Portugal) is provided. While the delamination from arches support can be modelled only in an approximate way within limit analysis, the aim of the paper is to accurately reproduce the change in the failure mechanism observed in experimentation, due to the introduction of strengthening elements. Both experimental and numerical results showa clear change in the failure mechanism and in the corresponding ultimate peak load. A set of simulations is also performed on reinforced arches previously damaged, to investigate the role played by the reinforcement within a proper repairing procedure. Good correlation with experimental work and numerical simulations is achieved.
\end{abstract}

Keywords: masonry curved arches, FE modelling, limit analysis, experimental results.

\section{INTRODUCTION}

The need for designing an efficient and non-invasive reinforcement intervention is a key issue to all technicians involved in the reconstruction and rehabilitation of buildings before and after structural damage. The structural analysis and rehabilitation of masonry constructions represent one of the most challenging aspects related to the protection and the maintenance of ancient and historical buildings.

Masonry arches and vaults representimportant constructive elements of ancient buildings all over the world. Additionally, many ancient arches and vaults are of considerable historical and architectural importance.

Among innovate techniques to rehabilitate deteriorated structures, there has been an increasing interest in fibre composite materials, commonly known as fibre reinforced polymers (FRP). The specific application of FRP in construction is highly attractive and cost-effective due to durability improvement, reduced life-cycle maintenance costs and also savings from easier transportation and enhancement of on-site productivity. During the last decades, considerable efforts have been done into the FRP application and effectiveness as material to enhance local and global structural behavior, particularly when hazard events occur such as earthquake effects.

The current paper deals with the experimental and numerical analysis of masonry arches reinforced with FRP strips at the intrados and at the extrados.

As well known, limit analysis is a valuable alternative to expensive non-linear FE simulations and has been widely used for the analysis at failure of masonry structures [1]. The adoption of an upper bound approach combined with FEM seems particularly suited for the prediction of FRP-masonry behavior prone to collapse. The limit analysis approach used here is based on the use a perfectly-plastic material response for masonry and for the FRP/masonry interface, i.e. softening effect and limited ductility cannot be considered [2] and [3].

Comparisons with experimental evidence confirm that the limit analysis approach proposed represents a valuable tool for predicting failure mechanisms and collapse loads of masonry arches reinforced with FRP strips.

The paper is organized as follows:2nd section describes the masonry arches characteristics, FRP glass materials (GFRP) used and the adopted experimental setup. The heterogeneous FE model adopted is outlined in the $3^{\text {rd }}$ section, wherealso numerical simulation results are critically discussed and compared with experimental data. Closing remarks are outlined in the last section.

${ }^{*}$ Corresponding author, e-mail: milani@stru.polimi.it, gabriele.milani@polimi.it, Phone: +39 0223994290.

International Conference of Computational Methods in Sciences and Engineering 2014 (ICCMSE 2014)

AIP Conf. Proc. 1618, 618-621 (2014); doi: 10.1063/1.4897816

(C) 2014 AIP Publishing LLC 978-0-7354-1255-2/\$30.00 


\section{EXPERIMENTAL SET-UP AND CONSTITUENT PROPERTIES}

In scale models are used for the experimentation. The purpose related with the use of scaled models is not to perform a scale analysis but rather to achieve a faster construction process and an easier testing setup. The quality of the results is not affected by not using similarity laws and the results remain valid for the use of numerical and analytical tools, with the restriction of not been able to extrapolate results directly to bigger, real arches.

Twelve arches were built, using 59 brick courses and with a semicircular shape with a span of $1500 \mathrm{~mm}$. The single ring thickness was equal to the brick height, $50 \mathrm{~mm}$, (thickness/span $\approx 1 / 30$ ) see Figure 1a.

All arches were constructed over a wooden mould keeping constant intrados mortar joint thickness of approximately $10 \mathrm{~mm}$. All arches were tested two weeks after its construction. Further construction details can be found in [4].

For easier reference the masonry arches were designated within the following nomenclature divided in four main categories:

- Unreinforced arches, US-n

- Localized reinforcement on unreinforced tested arches, LS-n

- Continuous reinforcement at the extrados, CSE-n and

- Continuous reinforcement at the intrados, CSI-n.

The letter $\mathrm{n}$ stands for the sequential specimen's number. A detailed description of all masonry arches tests is presented in Table 1; this table includes width of strips applied on each masonry reinforced arch.

TABLE 1. Experimental summary of masonry arches tested.

\begin{tabular}{|c|c|c|c|c|c|c|}
\hline \multirow[t]{2}{*}{ Specimen } & \multicolumn{2}{|c|}{$\begin{array}{c}\text { GFRP strip } \\
\text { width , w (mm) }\end{array}$} & \multicolumn{2}{|c|}{$\begin{array}{l}\text { Force, } \\
\text { F }(\mathrm{kN})\end{array}$} & \multirow{2}{*}{$\begin{array}{c}\text { Resistance } \\
\text { increase } \\
(\%)^{\mathrm{III}}\end{array}$} & \multirow{2}{*}{$\begin{array}{c}\text { Sustained } \\
\text { displacemen } \\
(\mathrm{mm})\end{array}$} \\
\hline & Intrados & Extrados & Maximum & Average $^{\text {II }}$ & & \\
\hline US-1 & - & - & 1.43 & 168 & & 05 \\
\hline US-2 & - & - & 1.92 & 1.68 & - & 0.5 \\
\hline LS-1 & \multicolumn{2}{|c|}{150.0} & 3.18 & & & \\
\hline LS-2 & \multicolumn{2}{|c|}{150.0} & 2.73 & 2.96 & 76 & 0.9 \\
\hline CSE-1 & - & 100.0 & 2.51 & \multirow{2}{*}{3.17} & \multirow{2}{*}{89} & \multirow{2}{*}{15.5} \\
\hline CSE-2 & - & 100.0 & 3.82 & & & \\
\hline CSE-3 & - & 160.0 & 3.62 & \multirow{2}{*}{3.44} & \multirow{2}{*}{105} & \multirow{2}{*}{28.8} \\
\hline CSE-4 & - & 160.0 & 3.26 & & & \\
\hline CSI-1 & 100.0 & - & 4.26 & \multirow{2}{*}{4.45} & \multirow{2}{*}{165} & \multirow{2}{*}{35.9} \\
\hline CSI-2 & 100.0 & - & 4.63 & & & \\
\hline${ }^{\mathrm{I}} \mathrm{CSI}-3$ & 100.0 & - & 5.41 & \multirow{2}{*}{4.61} & \multirow{2}{*}{174} & \multirow{2}{*}{32.7} \\
\hline${ }^{\mathrm{I}} \mathrm{CSI}-4$ & 100.0 & _- & 3.81 & & & \\
\hline
\end{tabular}

${ }^{\mathrm{I}}$ Handmade FRP-based spike anchors were used in addition to the FRP strips.

II (US-1+US-2)/2 = Av

III $\operatorname{inc}(\%)=100 \times(\mathrm{S}-\mathrm{Av}) / \mathrm{Av}$

All masonry arches specimens were tested by means of a servo-controlled machine mounted with a $25 \mathrm{kN}$ cell capacity; the jack was positioned at the middle of the arch width. The load was applied at the quarter span (lateral view), as shown in Figure 1.The arches without reinforcement failed through the formation of a typical four-hinge mechanism. Collapse occurred in a brittle fashion for very small displacements. All reinforcement arrangements tested led to an increase of the load bearing capacity, but localized reinforcement does not seem to be a suitable strategy as it does not change the initial failure mechanism. On the other hand, this particular masonry arches test is considered as the most representative real case study of retrofitting among all the variants analyzed in this work.

For the masonry arches reinforced at the extrados, the first hinge was formed beneath the applied load, whereas the other two hinges appeared afterwards at the supports. Sliding of one part of the arch with respect to the other, along a mortar joint close to its support characterized the failure of this series due to insufficient shear resistance. Detachment of the FRP from the masonry substrate involving ripping of a thin layer of brick and mortar, as shown by post-mortem inspection, characterize the masonry arches reinforced at the intrados. Two of the hinges were formed at its supports and the third hinge appeared at the extrados opposite loading side, on the right half of the arch. Failure was determine by the successive detachment of the two strips. Reinforcement applied at the extrados provides the higher deformation capacity prior to failure, endowing arches with an important ductility behavior of this masonry arches reinforcement type. 


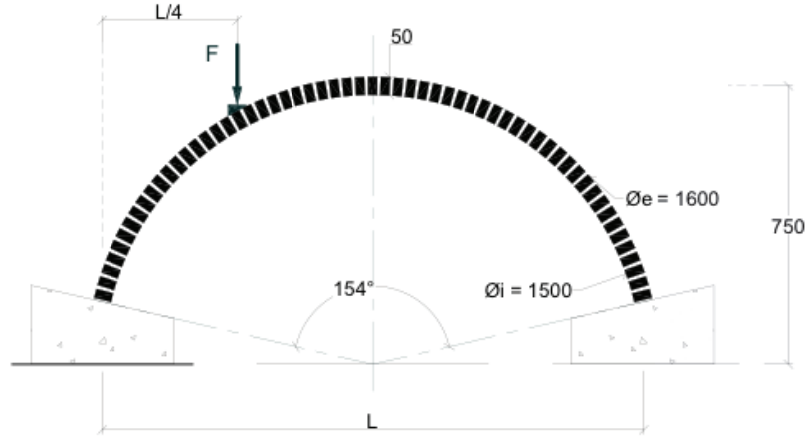

(a)

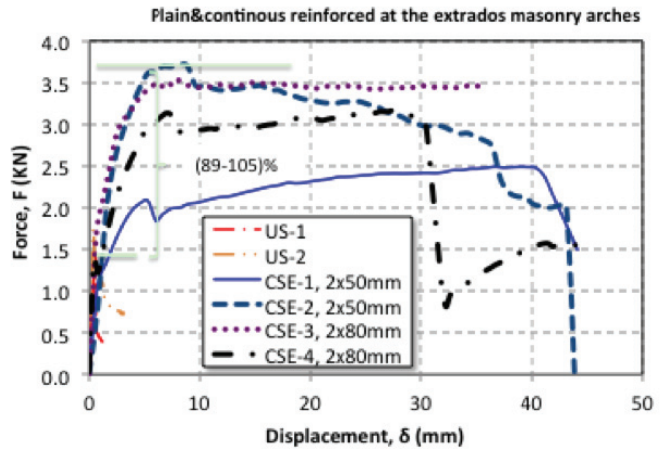

(b)

FIGURE 1. Masonry arches: (a) geometry, dimensions in ( $\mathrm{mm}$ ) and (b) vertical load vs displacement diagrams measured at loading point for plain specimens comparing peak load reached with continuous reinforced at the extrados (CSE).

TABLE 2. Comparison between experimental and numerical (limit analysis) collapse loads

\begin{tabular}{|c|c|c|c|c|c|c|}
\hline \multirow[t]{2}{*}{ Specimen } & \multicolumn{2}{|c|}{$\begin{array}{c}\text { GFRP strip } \\
\text { width , w (mm) }\end{array}$} & \multicolumn{2}{|c|}{$\begin{array}{c}\text { Experimental collapse load } \\
\mathrm{F}(\mathrm{kN})\end{array}$} & \multirow{2}{*}{$\begin{array}{c}\text { Numerical } \\
\text { (UB limit } \\
\text { analysis) }\end{array}$} & \multirow[t]{2}{*}{ Error $(\%)$} \\
\hline & Intrados & Extrados & Maximum & Average $^{\mathrm{II}}$ & & \\
\hline US-1 & - & - & 1.43 & 168 & 188 & 1100 \\
\hline US-2 & - & - & 1.92 & 1.00 & 1.00 & 11.90 \\
\hline LS-1 & \multirow{2}{*}{\multicolumn{2}{|c|}{$\begin{array}{l}150.0 \\
150.0\end{array}$}} & 3.18 & \multirow{2}{*}{2.96} & \multirow{2}{*}{3.23} & \multirow{2}{*}{9.12} \\
\hline LS-2 & & & 2.73 & & & \\
\hline CSE-1 & - & 100.0 & 2.51 & \multirow{2}{*}{3.17} & \multirow{2}{*}{4.01} & \multirow{2}{*}{26.50} \\
\hline CSE-2 & - & 100.0 & 3.82 & & & \\
\hline CSE-3 & - & 160.0 & 3.62 & \multirow{2}{*}{3.44} & \multirow{2}{*}{3.68} & \multirow{2}{*}{6.97} \\
\hline CSE-4 & - & 160.0 & 3.26 & & & \\
\hline CSI-1 & 100.0 & - & 4.26 & \multirow{2}{*}{4.45} & \multirow{2}{*}{4.55} & \multirow{2}{*}{2.25} \\
\hline CSI-2 & 100.0 & - & 4.63 & & & \\
\hline${ }^{\mathrm{I}} \mathrm{CSI}-3$ & 100.0 & - & 5.41 & \multirow{2}{*}{4.61} & \multirow{2}{*}{4.89} & \multirow{2}{*}{6.07} \\
\hline${ }^{\mathrm{I}} \mathrm{CSI}-4$ & 100.0 & - & 3.81 & & & \\
\hline
\end{tabular}

\section{FE LIMIT ANALYSIS MODEL: BASIC ASSUMPTIONS AND DISCUSSION OF THE RESULTS}

A heterogeneous limit analysis is conducted on the arches experimentally tested, modelling the structure by means of the FE approach firstly proposed in [3] [5] [6]. Here, for the sake of conciseness, only the basic assumptions of the model are recalled, whereas the reader interested in details is referred to [5].

Basically, the model consists in a FE discretization of the structure through a distinct representation of blocks and mortar. Namely, eight-noded infinitely resistant elements are used for bricks, which interact by means of rigidplastic interfaces representing mortar joints. The eventually present external reinforcement is taken into consideration by means of the introduction of four-noded infinitely resistant plate elements. Delamination from the support is accounted for with the introduction of a rigid plastic interface between bricks and FRP, with peak strength assumed equal to peak delamination provided by Italian Guidelines CNR DT200[7] dealing with the reinforcement of masonry and concrete structures. A possible rupture of the strip for axial load is also possible at the interface between contiguous FRP elements. Strips do not contribute in compression, since it is assumed very low compression strength at the same interfaces.In the framework of the aforementioned modelling, a simple linear programming problem is derived involving very few variables, thanks to bricks modelling by means of infinitely resistant elements. The FE code allows also the analysis of double curvature structures. In Figure 2, the failure mechanisms found with the FE approach proposed are represented in absence and presence of reinforcement at the extrados (CSE-n). The failure mechanism changes considerably with FRP, exhibiting sliding on plastic hinges.In Table 2, a comparison between experimental and numerical collapse loads is provided. As can be seen, the simple 
limit analysis procedure adopted allows a fast and reliable estimation of both collapse loads and failure mechanisms, both in absence and presence of FRP strengthening in various configurations.It therefore may represent a valuable tool for all practitioners interested in an inexpensive estimation of the increase of the load carrying capacity that may be obtained with the introduction of a suitable strengthening intervention.

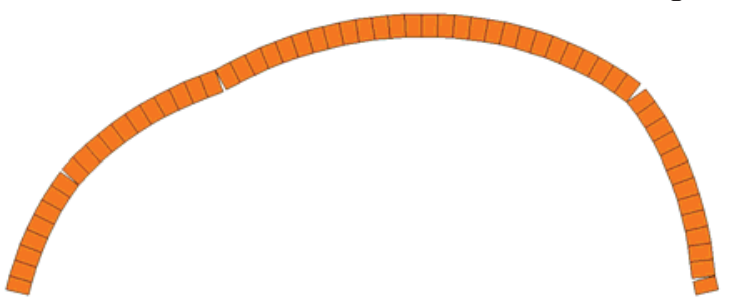

(a)

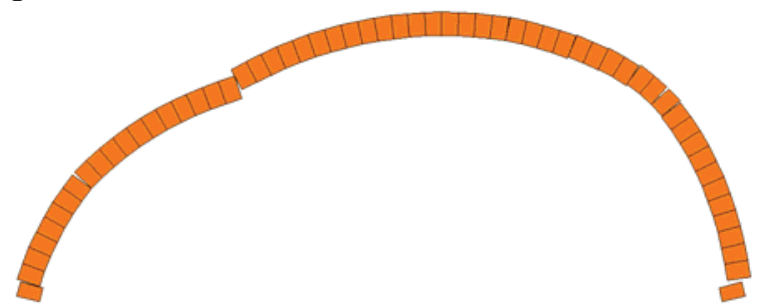

(b)

FIGURE 2. Masonry arches. Numerical deformed shape at collapse in absence of reinforcement (a), and with continuous extrados reinforcement CSE-n (b).

\section{CLOSING REMARKS}

A heterogeneous FE limit analysis approach for the fast evaluation of collapse loads and failure mechanisms of FRP-reinforced masonry circular arches has been presented, basing on a huge amount of experimental results obtained at the University of Minho (Portugal). The aim of the present experimental and numerical investigation was focused on obtaining the following objectives:

- Characterization of the structural behavior of unreinforced and reinforced masonry arches monotonically loaded, including the softening regime, which is usually absent from literature;

- Assessment of the influence of the reinforcement arrangements on the mechanical behavior and failure mode in terms of load capacity, ductility, and failure modes;

- Consistently reproduce the change in the failure mechanism observed inexperimentations due to the introduction of reinforcement elements, such as FRP, in presence of curved surfaces (i.e. where delamination strength may be variable [8]).

The predictions provided by the FElimit analysis model proved to be effective and approximate reasonably well the experimental information.

\section{REFERENCES}

1. G. Milani G, P. B. Lourenço and A.Tralli, Homogenised limit analysis of masonry walls. Part I: failure surfaces. Comp Struct. 84, 166-80(2006).

2. R. Fedele and G. Milani, Assessment of bonding stresses between FRP sheets and masonry prisms during delamination tests. Comp Part B. 43, 1999-2011 (2012).

3. G. Milani, 3D FE limit analysis model for multi-layer masonry structures reinforced with FRP strips. Int. J. Mech. Scien. 52, 784-803 (2010).

4. I. Basilio, "Strengthening of arched masonry structures with composite materials", Ph.D. Thesis University of Minho, Guimarães, 2007, pp. 110-135. Can be downloaded from: http://www.civil.uminho.pt/ masonry/ Publications/ Update Webpage/ $2007 \mathrm{PhD}$ IsmaelBasilio.pdf.

5. E. Milani,G. Milani,andA. Tralli, Upper Bound limit analysis model for FRP-reinforced masonry curved structures. Part II: structural analyses. Computers \& Structures, 87 (23-24), 1534-1558(2009).

6. G. Milani, P.B. Lourenço, Simple homogenized model for the non-linear analysis of FRP strengthened masonry structures. Part I: theory. Journal of Engineering Mechanics ASCE, 139 (1), 59-76 (2013).

7 CNR-DT-200 R1. Istruzioni per la Progettazione, l'Esecuzione ed il Controllo di Interventi di Consolidamento Statico mediante l'utilizzo di Compositi Fibrorinforzati. ConsiglioNazionaledelleRicerche, Rome, Italy. 2012.

8. I. Basilio, R. Fedele, P. B. Lourenço, and G. Milani, Assessment of curved FRP-reinforced masonry prisms: experiments and modeling. Const.Buil. Mat.51, 492-505 (2014). 